\title{
Growth and mortality of juvenile white shrimp Litopenaeus setiferus in a marsh pond
}

\author{
Ronald Baker, Thomas J. Minello* \\ National Oceanic and Atmospheric Administration, NMFS, Southeast Fisheries Science Center, Galveston Laboratory, \\ 4700 Avenue U, Galveston, Texas 77551, USA
}

\begin{abstract}
Despite the widely held view that certain estuarine habitats are more valuable as nurseries because they provide enhanced growth and reduced mortality, there remain few estimates of growth and mortality rates in support of this paradigm. We conducted field caging experiments and collected weekly nekton samples in shallow open-water habitat in a marsh pond during summer and fall 2007 in Galveston Bay, Texas, USA, to estimate growth and morality rates of juvenile white shrimp Litopenaeus setiferus. Growth rates (mean $\pm 1 \mathrm{SE}$ ) were lower during the summer experiment $\left(0.77 \pm 0.05 \mathrm{~mm} \mathrm{~d}^{-1}\right)$ than the fall $\left(0.91 \pm 0.04 \mathrm{~mm} \mathrm{~d}^{-1}\right)$, and high summer water temperatures may have inhibited shrimp growth. Cohort analysis to derive mortality estimates from 15 weekly sampling trips failed due to extended periods of continuous recruitment, the lack of clearly identifiable cohorts, and high temporal variability in abundance estimates. Catch-curve analysis provided estimates of mean daily instantaneous mortality $(Z)$ during the sampling period of 0.181 for post-larvae and early juveniles $<28 \mathrm{~mm}$ TL and 0.083 for larger juveniles $>28 \mathrm{~mm}$. The mortality estimates must be interpreted with caution due to potential problems meeting the assumptions of catch-curve analysis. Despite the challenges, comparisons of vital rates among habitats are required to validate long-held paradigms on the functioning of estuarine nurseries and the importance of various coastal habitats in the support of fishery species.
\end{abstract}

KEY WORDS: Nursery-ground ecology $\cdot$ Salt marsh $\cdot$ Essential fish habitat $\cdot$ Mesocosm experiment · Cohort analysis · Catch-curve analysis

\section{INTRODUCTION}

Shallow estuarine habitats are considered to be valuable nurseries for a variety of species, including many of ecological and commercial significance (Boesch \& Turner 1984, Beck et al. 2001). In an effort to prioritize management, conservation, and restoration efforts, the assessment of the relative values or importance of a variety of estuarine habitats as nurseries has generated a large body of literature. A fundamental paradigm of estuarine nursery-ground ecology is that valuable nursery habitats provide juveniles with some combination of high food availability and refuge from predation, which ultimately results in greater population fitness. Despite the clear implications that certain habi- tats therefore provide enhanced growth and/or reduced mortality, there remain few estimates of growth or mortality rates within estuarine habitats (Heck et al. 2003, Kneib 2003, Minello et al. 2003, Fry 2008, Shervette \& Gelwick 2008), and fewer demonstrations of the mechanistic links or functional roles of various habitats in regulating growth and mortality of juvenile nekton (Sheaves et al. 2006).

In the northern Gulf of Mexico (GoM), salt marshes and the adjacent shallow open water support high densities of many species of juvenile nekton including white shrimp Litopenaeus setiferus (Peterson \& Turner 1994, Howe et al. 1999, Minello et al. 2008). The paucity of data on growth and mortality in the GoM and elsewhere in the world reflects the challenges of 
measuring these for mobile nekton populations in complex and dynamic estuarine landscapes (Kneib 1997, Rountree \& Able 2007). Traditional fishery methods for deriving estimates of vital rates applied to white shrimp are further complicated because crustaceans cannot be reliably aged from hard structures such as the otoliths, scales, and bones of fishes. The few published estimates of growth rates for juvenile white shrimp in marsh habitats have been derived from mark-recapture methods (Knudsen et al. 1996, Webb \& Kneib 2004) or caging and mesocosm experiments (Shervette \& Gelwick 2008, Rozas \& Minello 2009). The mark-recapture approach has the benefit of providing growth estimates of shrimp ranging freely with the opportunity to access a variety of habitats according to normal behaviors and as dictated by preferences for environmental conditions. However, this approach requires significant logistical effort given the relatively low recapture rates of marked individuals in dynamic estuarine landscapes (Knudsen et al. 1996, Webb \& Kneib 2004), and it does not provide habitat-specific estimates of growth. In contrast, caging experiments can provide growth estimates from specific habitat types. However, experimental artifacts caused by enclosing animals and restricting their movement need to be carefully considered when making comparisons of growth among habitats from these experiments (Peterson \& Black 1994, Rozas \& Minello 2009).

Mortality estimates for white shrimp are similarly scarce, and have been derived from mark-recapture of individuals exiting an enclosed marsh pond in Louisiana (Knudsen et al. 1996) and from catch-curve analysis of a long-term data set of shrimp samples from marsh habitats in Galveston Bay, Texas, USA (Minello et al. 2008). Like any method used to estimate mortality, these approaches necessarily make a number of assumptions about shrimp recruitment, migrations, and probability of sampling/recapture.

Despite the challenges, estimates of growth and mortality rates in a variety of estuarine habitats are fundamentally important for validating paradigms on nursery ground functioning. The goal of the present study was to determine growth and mortality rates of juvenile white shrimp inhabiting a marsh pond. We measured growth during the summer and fall using cages on nonvegetated bottom. We compared growth rates between 2 locations ( 1 and $30 \mathrm{~m}$ from marsh vegetation), because earlier work showed that densities of white shrimp were higher near the marsh vegetation (Minello et al. 2008), and we hypothesized that growth might vary between these nonvegetated habitats or locations. Shrimp densities were measured throughout the summer and fall in the pond, and a catch curve analysis was used to estimate shrimp mortality rates. Such data serve as a foundation for examining the role of habitats in regulating growth and mortality of juvenile shrimp in coastal nurseries. Understanding the processes underlying habitat use is critical for the identification of essential habitats and for the effective management and conservation of coastal wetlands and the fisheries that rely on them (Sheaves et al. 2006, Rountree \& Able 2007).

\section{MATERIALS AND METHODS}

Study site. Growth experiments and sampling to estimate mortality were conducted in a 7.2 ha semienclosed marsh pond in the marsh complex along the bayside of Galveston Island (29 $15^{\prime} 30^{\prime \prime} \mathrm{N}, 94^{\circ} 55^{\prime} 0^{\prime \prime} \mathrm{W}$; Fig. 1). The pond is surrounded by intertidal vegetated marsh dominated by Spartina alterniflora. The pond is continuously connected to Gangs Bayou via 2 channels, each approximately 10 to $15 \mathrm{~m}$ wide and $150 \mathrm{~m}$ long. The tides in the region are semi-diurnal, and the maximum range during the study was $0.6 \mathrm{~m}$. Tides in the northern GoM are strongly driven by climatic conditions and weather patterns, so actual tide heights regularly deviate considerably from predicted tides (Rozas 1995).

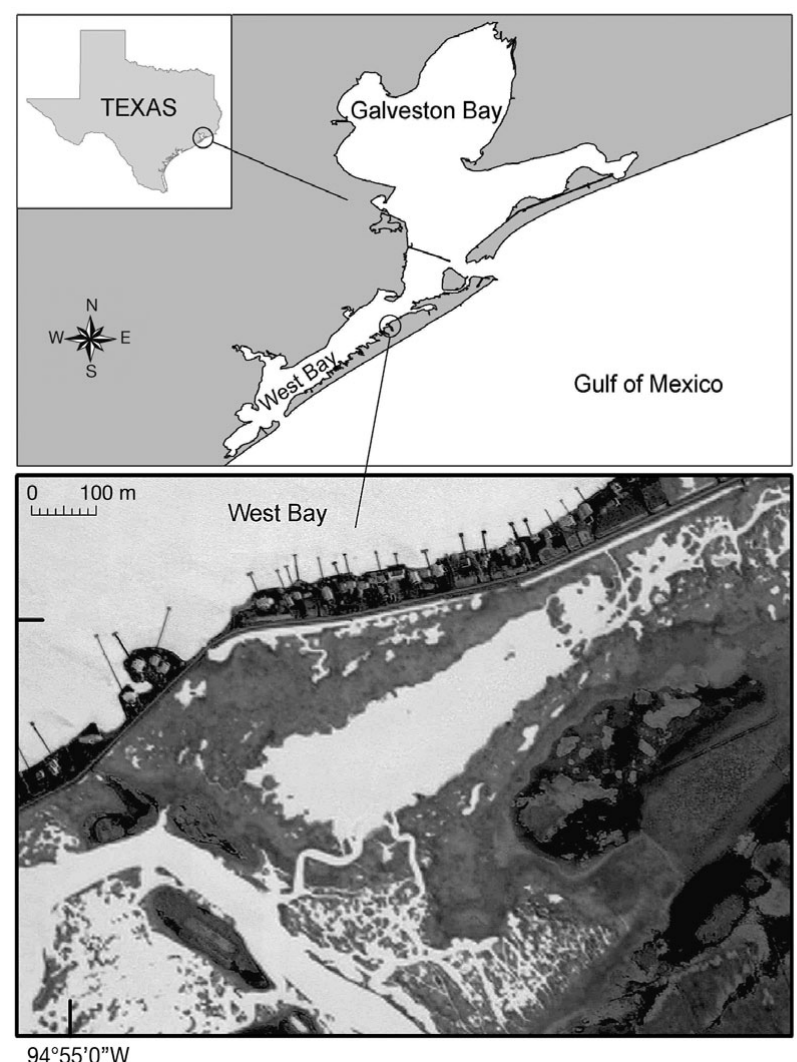

Fig. 1. Study site showing the marsh pond in the center of the lower panel, adjacent to West Bay on Galveston Island. The 2 creeks connecting the pond to Gangs Bayou can be seen at the southern corner of the pond 
This semi-enclosed marsh pond was chosen for a number of reasons. We believed that limited connectivity with open waters of the adjacent marsh complex would minimize the likelihood of significant migration of post-settlement juvenile shrimp to and from the pond during the study. No net migration is an important assumption of estimating mortality rates though either catch-curve or cohort analysis (see 'Mortality estimates' below). In addition, the site has been the location of several previous studies on the small-scale distribution of shrimp in wetland landscapes (Minello \& Rozas 2002, Minello et al. 2008) and on the distribution of benthic infauna (Whaley \& Minello 2002), important prey of juvenile white shrimp (Hunter \& Feller 1987, McTigue \& Zimmerman 1991, Beseres \& Feller 2007).

Growth experiments. Two $7 \mathrm{~d}$ field caging experiments were conducted in the pond to estimate juvenile white shrimp growth rates, Expt 1 from August 1 to 8 and Expt 2 from October 2 to 9, 2007. Each experiment involved caging shrimp in circular $1 \mathrm{~m}^{2}$ open-bottomed cages covered with 2-mm mesh. Fourteen cages were located randomly, with a minimum separation of $5 \mathrm{~m}$, along a section of shoreline on shallow nonvegetated bottom of the pond. Seven cages each were placed at $1 \mathrm{~m}$ and $30 \mathrm{~m}$ from the marsh edge to test the hypothesis that observed shrimp distribution patterns, with high densities near $(<5 \mathrm{~m})$ the marsh edge rapidly declining into open water (Minello et al. 2008), may be related to spatial patterns in food availability. The pond bottom is flat, and the difference in mean water depth around cages at $1 \mathrm{~m}$ and $30 \mathrm{~m}$ from the marsh edge was $0.7 \mathrm{~cm}$ and $2.5 \mathrm{~cm}$ during Expts 1 and 2, respectively.

On the first day of each growth experiment, we seined shrimp to stock cages from the adjacent bayou outside the pond to avoid disturbing the pond bottom or impacting the pond shrimp population being concurrently sampled for mortality estimates. All shrimp were held (max $6 \mathrm{~h}$ ) in aerated containers with regular water changes to minimize handling stress on the experimental animals. The initial size of stocked shrimp ranged from 28 to $74 \mathrm{~mm}$ total length (TL) $($ mean $\pm 1 \mathrm{SE}=49.1 \pm 1.3)$ for Expt 1 and 31 to $74 \mathrm{~mm}$ TL $(48.0 \pm 1.2)$ for Expt 2 . Shrimp were divided into 5 approximately equal size classes spanning the size range, with 1 individual from each size class stocked into each cage. This approach ensured a wide and even range of shrimp sizes in each cage and was used to avoid any bias caused by a potential relationship between shrimp size and growth rate. The stocked density of 5 shrimp $\mathrm{m}^{-2}$ is equivalent to predicted ambient density of white shrimp $1 \mathrm{~m}$ from marsh vegetation (Minello et al. 2008). While this same density stocked into cages $30 \mathrm{~m}$ from vegetation is $>5 \times$ pre- dicted mean ambient densities at this distance, it is well within the range of naturally occurring densities of white shrimp in open waters adjacent to marsh vegetation in Galveston Bay (Minello et al. 2008). Stocking multiple shrimp per cage also minimizes the probability of failing to recover at least some shrimp at the end of the experiment, thereby maximizing data returns for effort.

Shrimp were individually measured (TL, mm) and injected with either orange or yellow elastomer in the fourth, fifth or sixth abdominal segment musculature to provide a unique tag for each individual in a cage. Shrimp with broken rostra were not used as experimental animals. A tank experiment comparing growth and mortality over $1 \mathrm{wk}$ among $\mathrm{n}=75$ shrimp with either 0,1 , or 2 tags found no effect of the tagging method on either growth (ANOVA, $F_{2,72}=0.68, \mathrm{p}=$ 0.51 ) or mortality rates (no mortality recorded) . Excess shrimp collected at the commencement of each experiment (Expt 1, n = 98; Expt 2, n=49) spanning the same size range as those caged were retained to derive length-weight relationships and allow estimation of the initial weight of tagged shrimp. Although a direct measure of initial shrimp weight would have been preferable, it is difficult to obtain accurate weight measures of live shrimp in the field while minimizing handling stress of the experimental animals. Water temperatures were recorded hourly by Onset ${ }^{\mathrm{TM}} \mathrm{HOBO}$ Temperature Loggers placed on the substrate in each cage, and water depth recorded every $10 \mathrm{~min}$ by 2 Onset $^{\mathrm{TM}}$ HOBO U20 water level loggers, one attached to each of the shallowest $1 \mathrm{~m}$ and $30 \mathrm{~m}$ cages.

After $7 \mathrm{~d}$, shrimp were recovered from the cages by sliding a solid-framed recovery net through the surface layer of sediment under each cage and raising the net with the enclosed cage above the waters' surface. Individuals were identified by their elastomer tags, measured (TL, mm), and weighed (blotted wet wt $\mathrm{g}$ ). None of the recovered tagged shrimp had broken rostra. To confirm that our use of size classes ensured consistent distribution of shrimp sizes among cages, and to test for any difference in size of recovered shrimp among cages that could interact with a shrimp size-growth rate relationship to bias our growth comparisons, we compared both the mean initial, and mean final size of shrimp among cages by 1-way ANOVA. Individual growth rates were determined from the measured change in TL over the $7 \mathrm{~d}$ period $\left(\mathrm{mm} \mathrm{d}^{-1}\right)$, and from the difference between the final measured weight and the initial weight predicted from the initial lengthweight relationship $\left(\mathrm{g} \mathrm{d}^{-1}\right)$. We used the mean growth rate per cage as the observation in a 2-way ANOVA comparing growth among locations or habitats (1 or $30 \mathrm{~m}$ from vegetation) and experiments (summer and fall). Levene's test confirmed homogeneity of variances 
$(p=0.16)$, and an examination of residuals indicated no large deviations from normality. The relationship between initial size TL and individual shrimp growth rate was explored by regression.

Mortality estimates. Salt marshes in Galveston Bay are flooded through much of the year, and the highest densities of shrimp occupy the first few meters of vegetated marsh when this habitat is flooded (Minello et al. 2008). By combining shrimp distribution models and a GIS analysis of the pond sensu Minello et al. (2008), we estimated that $50.8 \%$ of the population of white shrimp occupying the pond and surrounding vegetation would be in open water at high tide, at a mean density of $1.1 \mathrm{~m}^{-2}$. Because quantitative sampling of shrimp and other nekton in large areas of vegetated marsh is difficult and time consuming (Rozas \& Minello 1997), we restricted our sampling to nonvegetated bottom, where at least half the population should be available to our gear.

We attempted to track individual cohorts through time and provide multiple estimates of juvenile mortality (e.g. Minello et al. 1989) by sampling the population of shrimp in shallow open water of the pond weekly for 15 wk from July 5 until October 11, 2007. Daytime water levels were high throughout this period, and on each sampling occasion the marsh edge was flooded to a depth between 15 and $60 \mathrm{~cm}$. Nekton were sampled using a $1 \mathrm{~m}$ wide $\times 0.8 \mathrm{~m}$ high benthic sled fitted with a $2 \mathrm{~mm}$ mesh net. The sled was towed by hand at approximately $1 \mathrm{~m} \mathrm{~s}^{-1}$ by 2 operators using $10 \mathrm{~m}$ tow ropes. Once positioned at the start of a replicate tow, the operators moved to the end of the tow ropes diagonally away from the tow path to minimize disturbance of the area to be sampled, and maintained separation for the length of the tow before converging again at the marsh edge to lift the sled. Field trials comparing the sled catch with that from a quantitative drop sampler (Zimmerman \& Minello 1984) indicated that the sled provides comparable density (sled, $\mathrm{n}=26: 10.5 \pm$ 2.5 shrimp $\mathrm{m}^{-2}$; drop sampler, $\mathrm{n}=18$ : $8.9 \pm 3.1 ; t_{42}=$ $0.42, p=0.68$ ) and size structure (Kolmogorov-Smirnov $\mathrm{d}_{\text {crito.05 }}=7.55, \mathrm{~d}_{\max }=4.26$ ) estimates for white shrimp in shallow open waters. For the first 5 wk, 10 replicate samples were collected during each sampling period; for subsequent sampling periods, we collected 15 replicate samples. Fifteen replicates represent a total swept area of $750 \mathrm{~m}^{2}$ on any sampling occasion, approximately $1 \%$ of the total pond open-water area (7.2 ha) and $0.5 \%$ of the shrimp population. Consequently, we assumed that the removal of individuals through sampling would have minimal impact on the pond population. Replicates were located randomly around the $\sim 1300 \mathrm{~m}$ perimeter of the pond with a minimum distance of $20 \mathrm{~m}$ between tows. Each replicate involved a $50 \mathrm{~m}$ sled tow made perpendicular to the marsh edge starting $50 \mathrm{~m}$ into open water (close to the centre of the pond at its narrowest) and ending at the edge of the vegetation. This sampling design was used to integrate densities across an expected gradient (highest densities nearest the marsh vegetation) (Minello et al. 2008) and provide an unbiased density estimate for the entire unvegetated area of the pond. Cohort analysis could potentially detect variable mortality rates among cohorts or among sampling intervals during our study (see below). Because variations in physical conditions may influence mortality, a subsurface $(5$ to $10 \mathrm{~cm}$ ) water sample was collected adjacent to the tow path at approximately the mid-point of each tow by one of the sled operators to measure salinity and turbidity, ensuring the water collection site was not disturbed by turbidity plumes created by the samplers. Water depth was also measured at the edge of the marsh vegetation where each sled tow ended.

Nekton collected in sled tows were placed on ice until they could be identified and measured in the laboratory. When shrimp TL could not be measured due to broken rostra $(\mathrm{n}=116)$, carapace length $(\mathrm{CL})$ was measured and converted to TL using the relationship $\mathrm{TL}(\mathrm{mm})=4.944 \mathrm{CL}(\mathrm{mm}), \mathrm{R}^{2}=0.964$, derived from 572 shrimp sampled from the pond. Length frequency distributions for white shrimp sampled on each date were converted to age-frequency distributions based on a pooled initial size-growth rate relationship from the growth experiments conducted in the pond for shrimp $\geq 28 \mathrm{~mm}$. For shrimp $<28 \mathrm{~mm}$ we assumed a constant growth rate of $1.23 \mathrm{~mm} \mathrm{~d}^{-1}$, the mean growth rate for $28 \mathrm{~mm}$ shrimp from our experiments. We considered this an appropriate compromise between back-extrapolating the observed TL growth rate relationship from our experiments (which would estimate $6 \mathrm{~mm}$ post-larvae [PL] growth rate at $1.69 \mathrm{~mm} \mathrm{~d}^{-1}$ ) and published growth estimates of $0.75 \mathrm{~mm} \mathrm{~d}^{-1}$ for PL in laboratory experiments using similar salinities and temperatures to our field experiments (Zein-Eldin \& Griffith 1969). Ages are presented as the estimated number of d since $6 \mathrm{~mm}$ TL, the size of the smallest PL sampled during the study.

We employed 2 approaches to estimate mortality. We attempted to derive multiple estimates of mortality by tracking the decline in cohort abundance through time by cohort analysis using FiSAT II (Gayanilo et al. 2005). Cohort analysis assumes recruitment in discrete pulses and that the abundance of cohorts can be tracked through time; this analysis allows for the measurement of variable mortality rates among cohorts or sampling intervals. We also used a catch-curve analysis (Ricker 1975) on the total pooled age structure from all sampling dates to derive estimates of mean mortality during the study period. Catch-curve analysis assumes more static population dynamics with approximately 
constant recruitment and mortality during the sampling period. The declining limb of the size frequency distribution converted to age frequency (the catchcurve), then represents the loss of individuals through mortality (Ricker 1975). Both approaches assume negligible post-recruitment migration to or from the population being sampled, and that the population is sampled randomly. The limited data available on juvenile white shrimp densities lacks sufficient temporal resolution, and we could not predict a priori recruitment patterns to the pond and hence which approach would be most valid. Both approaches have been previously applied to mortality estimates for penaeid shrimp in the region (Minello et al. 1989, 2008), and our sampling design allowed for either approach to be used.

\section{RESULTS}

\section{Growth experiments}

At the end of Expt 1, 86\% of tagged shrimp were recovered, with between 2 and 5 recovered from each cage. All 5 tagged shrimp were recovered from 8 of the 14 cages. Similarly, $83 \%$ of tagged shrimp were recovered at the end of Expt 2, with between 2 and 5 recovered per cage, and all 5 shrimp were recovered from 7 of the 14 cages.

The mean $( \pm 1$ SE throughout) growth rate of white shrimp was significantly higher in October (Expt 2) $\left(0.91 \pm 0.04 \mathrm{~mm} \mathrm{~d}^{-1}\right)$ than August (Expt 1) $(0.77 \pm$ $0.05 \mathrm{~mm} \mathrm{~d}^{-1}$ ) (ANOVA, $\left.F_{1,24}=5.49, \mathrm{p}=0.028\right)$. No significant effect of habitat (1 or $30 \mathrm{~m}$ from marsh) was detected during either experiment. There was a significant negative linear relationship between initial shrimp size and growth rate $\left(\mathrm{mm} \mathrm{d}^{-1}\right)$, with smaller shrimp growing faster than larger ones in both experiments (Fig. 2). The allocation of one shrimp from each size class to each cage was intended to eliminate any bias caused by this relationship, and no significant difference was detected in the mean size of shrimp either stocked (ANOVA, $F_{27,112}=0.10, \mathrm{p}>0.99$ ), or recovered from experimental cages $\left(F_{27,91}=0.42, \mathrm{p}=0.99\right)$. Mean increase in biomass of shrimp across both habitats and experiments was $0.043 \pm 0.002 \mathrm{~g} \mathrm{~d}^{-1}$. In contrast to growth measured in $\mathrm{mm} \mathrm{d}^{-1}$, there was no significant effect of experiment on growth rates measured in $\mathrm{g} \mathrm{d}^{-1}$. However, because initial shrimp mass was estimated from the regression between TL and weight rather than being measured directly, the precision in our estimates of biomass increase may have been insufficient to detect any real differences in growth rates using this dependent variable.

The mean minimum and maximum water temperatures recorded across the 14 cages for the duration of

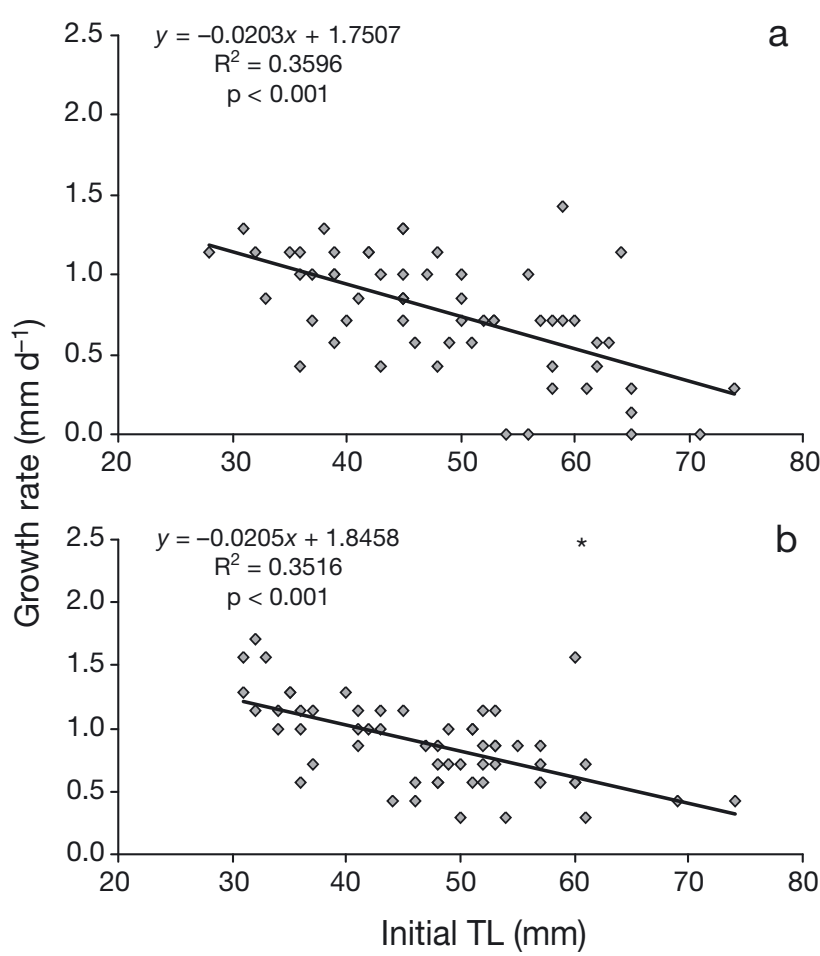

Fig. 2. Litopenaeus setiferus. Effect of initial size (total length, TL) on growth rate during caging experiments in a marsh pond. (a) Expt 1, August 1-8; (b) Expt 2 October 2-9, 2007. ${ }^{*}$ Outlier in (b) was a $60 \mathrm{~mm}$ individual with a growth rate of $2.4 \mathrm{~mm} \mathrm{~d}^{-1}$ and was excluded from analysis

Expt 1 ranged from $26.7 \pm 0.13\left(\min 26.0^{\circ} \mathrm{C}\right)$ to $38.6 \pm$ $0.28\left(\max =39.5^{\circ} \mathrm{C}\right)$. Water depth in the cages ranged between 0.08 and $0.39 \mathrm{~m}$. The lowest tides occurred during the second half of the experiment at night and coincided with low water temperatures. During Expt 2, temperatures ranged from $26.6 \pm 0.06\left(\min 26.1^{\circ} \mathrm{C}\right)$ to $32.8 \pm 0.14\left(\max 33.6^{\circ} \mathrm{C}\right)$, while water depth ranged from 0.22 to $0.81 \mathrm{~m}$. The lowest tides occurred in the first few days in the early evening and coincided with water temperatures in the mid-range of those measured.

\section{Mortality estimates}

A total of $>35000$ individuals from 56 taxa of nekton were sampled from the pond using the benthic sled. Six taxa made up $>90 \%$ of the catch, dominated by white shrimp Litopenaeus setiferus $(35.3 \%)$, bay anchovy Anchoa mitchilli (26.2\%), blue crab Callinectes sapidus $(15.7 \%)$, brown shrimp Farfantepenaeus aztecus $(10.0 \%)$, daggerblade grass shrimp Palaemonetes pugio $(2.3 \%)$, and spot Leiostomus xanthurus $(1.7 \%)$. White shrimp were abundant for the entire sampling period and were sampled at a mean density 
of $1.21 \pm 0.16 \mathrm{~m}^{-2}$ (Fig. 3). Shrimp post-larvae (PL) $\leq 15 \mathrm{~mm}$ TL were considered to be new recruits and were estimated to be $\sim 1 \mathrm{wk}$ post-settlement based on growth rates of small shrimp in our growth experiments (1.23 $\mathrm{mm} \mathrm{d}^{-1}$ for $28 \mathrm{~mm}$ shrimp) and the size structure of small PL sampled in our mortality study (Fig. 4). Recruitment to the pond occurred throughout the summer and fall with new recruits sampled on every occasion (Fig. 3).

Although some white shrimp cohorts could be identified and tracked from one week to the next, we could not derive mortality estimates through cohort analyses, because abundance estimates of individual cohorts were quite variable and recruitment pulses sporadic (Fig. 3). Because our GIS analysis suggested that about $49 \%$ of the white shrimp population in the pond would be present within the shoreline vegetation at high tide, we looked for a relationship between marsh flooding (water depth) and open water shrimp densities. For sampling periods when water depth at the marsh edge was $>25 \mathrm{~cm}$ there appeared to be no strong relationship. But when marsh edge depths were $<25 \mathrm{~cm}$, there appeared to be a strong negative relationship between shrimp densities in open water and the water depth at the edge of the marsh (Fig. 5a). The relationship between water depth and the density of larger shrimp only (>15 mm TL) was weaker and more variable (Fig. 5b).

The pooled age-frequency distribution indicated high mortality for PL and early juveniles $<28 \mathrm{~mm}$ TL (<18 d post-settlement) compared with older juveniles up to $70 \mathrm{~mm}$ (77 d post-settlement). Separate catchcurves were developed for these 2 age groups (Fig. 4). Shrimp larger than $70 \mathrm{~mm}$ were not included in the analysis; at approximately this size, they begin migrating to the open bay on their way offshore (Pullen \&

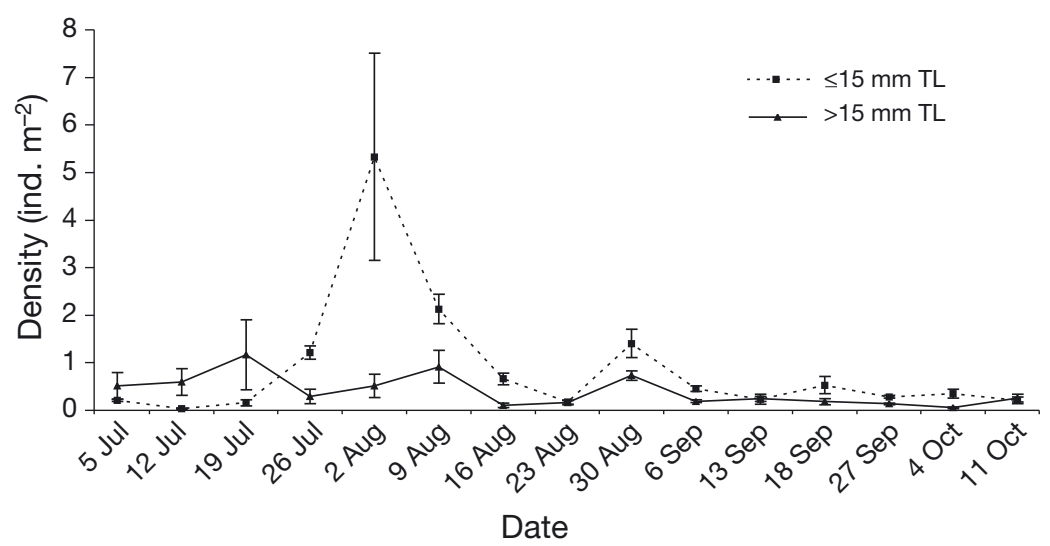

Fig. 3. Litopenaeus setiferus. Temporal patterns in mean $( \pm 1 \mathrm{SE})$ density in the marsh pond over $15 \mathrm{wk}$ through summer and fall 2007. Individuals $\leq 15 \mathrm{~mm}$ total length (TL) are assumed to be $\sim 1$ wk post-settlement based on our growth rate estimates for small juveniles $\left(1.23 \mathrm{~mm} \mathrm{~d}^{-1}\right)$ and the size structure of shrimp post-larvae sampled during this study (Fig. 4)
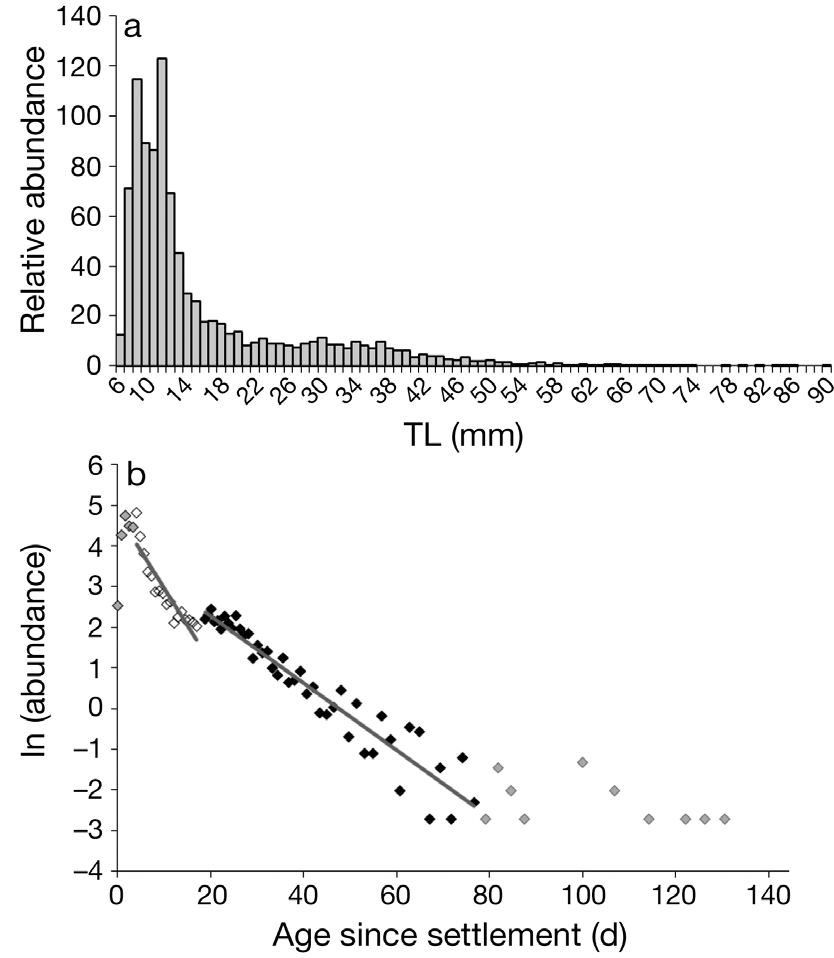

Fig. 4. Litopenaeus setiferus. (a) Pooled size-frequency distribution sampled over $15 \mathrm{wk}$ from a marsh pond on Galveston Island. (b) Size-frequency converted to age-frequency for catch-curve analysis with separate catch-curves fitted to $(\diamond)$ small juvenile shrimp 11 to $28 \mathrm{~mm}$ total length (TL) (4 to $18 \mathrm{~d}$ ) and $(\bullet)$ larger juveniles 28 to $70 \mathrm{~mm}$ TL (19 to $77 \mathrm{~d}$ ). Gray symbols: shrimp smaller and larger than those used to produce catch-curves

Trent 1969). Estimates of mean white shrimp daily instantaneous mortality rate $(Z)$ in the pond during the study period were 0.1806 for shrimp 11 to $28 \mathrm{~mm}$ TL and 0.0829 for shrimp 28 to $70 \mathrm{~mm}$. Small variations in the starting point of the catch-curve, or in the growth rate used to estimate age from length, had a large influence on estimates of $Z$ for early juveniles ( 0.15 to 0.20 ), while $Z$ estimates for larger juveniles $>28 \mathrm{~mm}$ remained stable.

\section{DISCUSSION}

\section{Growth experiments}

Juvenile white shrimp growth rates recorded in the present study (0.8 to $0.9 \mathrm{~mm} \mathrm{~d}^{-1}$ ) are within the range reported for free-ranging tagged white shrimp in a Louisiana, USA, marsh pond (0.3 to $1.4 \mathrm{~mm} \mathrm{~d}^{-1}$ ) (Knudsen et al. 1996) and are comparable to those recorded in 


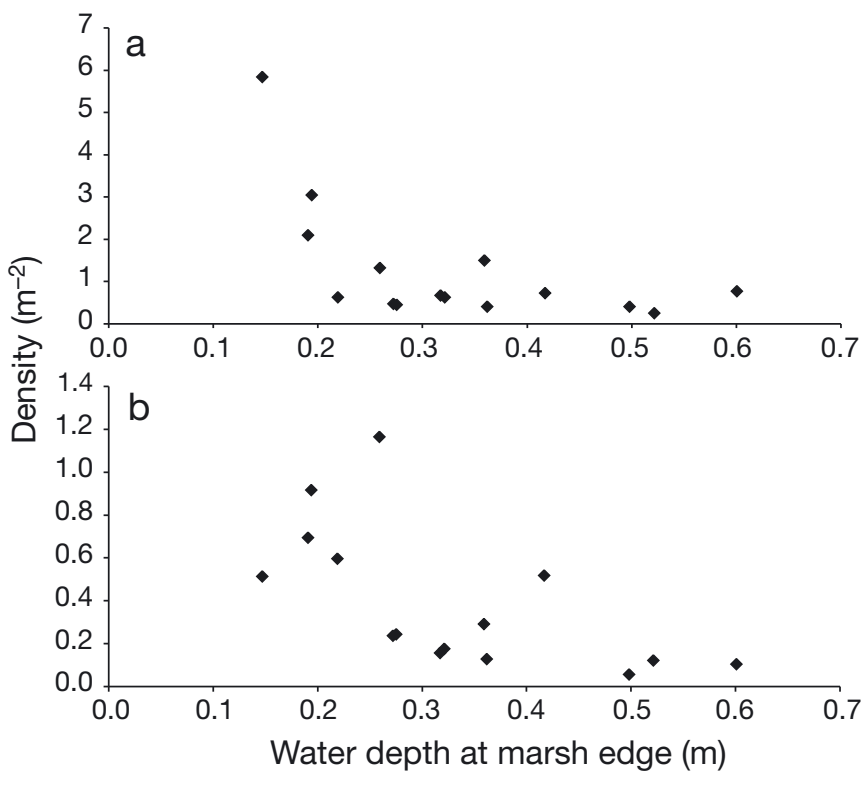

Fig. 5. Litopenaeus setiferus. Relationship between water depth at the marsh edge and density sampled from the adjacent open waters on each of 15 sampling occasions during mortality study. (a) All shrimp; (b) only shrimp >15 mm total length

Georgia (0.6 to $0.8 \mathrm{~mm} \mathrm{~d}^{-1}$ ) (Webb \& Kneib 2004). Our growth rates were also similar to those measured by Rozas \& Minello (2009) in another high salinity area of Galveston Bay using solid-walled mesocosms on nonvegetated bottom $\left(0.7 \mathrm{~mm} \mathrm{~d}^{-1}\right)$, but were 2 to $3 \times$ higher than those reported for caged white shrimp over nonvegetated bottom $\left(0.3 \mathrm{~mm} \mathrm{~d}^{-1}\right)$ at similar temperatures but lower salinities in a Mississippi, USA marsh (Shervette \& Gelwick 2008). Other caging experiments conducted in open waters of Louisiana marshes of varying salinities (L. P. Rozas \& T. J. Minello unpubl. data) found similar patterns, with growth rates of white shrimp in high-salinity marshes comparable to those in the present study, and growth rates for shrimp caged in low salinity marshes similar to those reported by Shervette \& Gelwick (2008). This pattern suggests that food limitation or shrimp physiology may limit growth in low salinity systems (Rosas et al. 1999). Additionally, the objective of the Shervette \& Gelwick (2008) experiment was to compare growth among habitats rather than measure absolute growth, and their combination of high caged shrimp densities $\left(>14 \mathrm{~m}^{-2}\right)$ and a relatively long experimental duration (16 d) may have contributed to an effect of food limitation on growth in their study.

Shrimp growth was significantly higher in October compared to August. This difference may have been related to the high water temperatures during the August experiment, particularly during periods of low water levels, because such high temperatures can inhibit white shrimp growth (Zein-Elden \& Griffith 1969). Although we did not measure infaunal abundance during our experiments, infaunal prey populations can be seasonally variable (Beseres \& Feller 2007) and potentially could have caused the difference in growth between August and October. However, Whaley \& Minello (2002) reported similar low infaunal biomass during both of these periods on nonvegetated bottom ( $1 \mathrm{~m}$ from the marsh) in this pond. We found no effect of location ( $1 \mathrm{~m}$ vs. $30 \mathrm{~m}$ from the marsh) on growth rates within the pond. Other research in the pond indicates that the biomass of benthic infauna was likely lower at $30 \mathrm{~m}$ from the marsh compared with $1 \mathrm{~m}$ (R. Culp unpubl. data). Combined with a lack of a location effect on growth, these data suggest that white shrimp growth was not limited during our experiments by infaunal prey abundance.

White shrimp appear to be important predators on benthic invertebrate prey (Beseres \& Feller 2007), but shrimp may derive nutrition from other sources such as benthic diatoms (Fry et al. 2003). McTigue \& Zimmerman $(1991,1998)$ found that white shrimp were capable of growing for short periods on a strictly herbivorous diet, but growth and survival were significantly enhanced when benthic infaunal prey were available. While apparently not a prominent part of the diet (Hunter \& Feller 1987), zooplankton also may have contributed to the nutritional support of our caged shrimp (Beseres Pollack et al. 2008). The mesh walls of the growth cages potentially provide a substrate for microalgae and shrimp prey, and this additional food source may compensate for real differences in growth potential among the habitat treatments tested. However, the similarity of our growth rates to those reported by Rozas \& Minello (2009) using solid-walled fiberglass cylinders as growth chambers, and to rates for free ranging shrimp in both Georgia (Webb \& Kneib 2004) and Louisiana (Knudsen et al. 1996), suggests that caging artifacts had little influence on shrimp growth in our 1 wk experiments. Longer experimental periods may exacerbate caging artifacts such as enhanced growth from fouling of mesh walls or depressed growth from prey depletion within the enclosed area.

The distribution of white shrimp in relation to marsh vegetation is considered indicative of habitat value. Earlier work suggested a lack of affinity for marsh vegetation by white shrimp (Zimmerman \& Minello 1984, Minello \& Zimmerman 1985), but more recent and comprehensive studies indicate that white shrimp show a strong affinity to marsh edge vegetation (Rozas et al. 2007). In addition, Minello et al. (2008) reported higher densities of white shrimp on nonvegetted bottom near the marsh $(<5 \mathrm{~m})$ compared with densities further from marsh vegetation. Our growth results suggest that white shrimp do not gain a significant 
growth advantage from feeding in open waters close to the marsh edge relative to more distant open waters. The shrimp density distribution on nonvegetated bottom therefore appears related to some aspect of the marsh itself rather than the open-water distribution of prey resources.

\section{Mortality estimates}

Cohort-analysis assumes that recruitment is pulsed in distinct events and that individual cohorts can be identified and tracked through time. We chose a shallow marsh pond as a study area believing that regular pulses of white shrimp recruits would appear in the samples and that these shrimp would remain in the pond until they were large enough to migrate out to the open bay. We expected that the limited connectivity with adjacent open waters would minimize migrations of post-settlement juvenile shrimp to or from the pond during the study, and that these conditions would allow us to estimate natural mortality through a cohort analysis. However, we were unable to identify regular cohorts and derive mortality estimates through this approach. Variability in water levels among sampling periods appeared partly responsible, apparently allowing variable access to the unsampled vegetated marsh surface and affecting our population estimates in open water. Tidal fluctuations also may have affected the dynamics of recruitment and migration to and from the pond. Although we were able to identify and track some cohorts, recruitment into the pond appeared to be continuous for extended periods, albeit with some intermittent large influxes of PL (Fig. 3). For these reasons, the application of catch-curve analysis was considered a more valid approach to estimate mortality.

Catch-curve analysis indicated high mortality for early post-settlement shrimp during the first month of residency in the marsh (Fig. 4b). The specific estimate for early juvenile mortality should be interpreted with caution because it is sensitive to selection of the starting point of the catch-curve. It is also sensitive to the growth rate estimate used to estimate age from length, and the available growth rate estimates are uncertain. It is difficult to tag shrimp smaller $(<28 \mathrm{~mm})$ than those used in our experiments $(\geq 28 \mathrm{~mm})$ due to high mortality during capture and handling. The only other available estimates for white shrimp PL growth rates ( $0.75 \mathrm{~mm} \mathrm{~d}^{-1}$ under similar salinities and temperatures) were derived from laboratory experiments employing artificial feeds (Zein-Eldin \& Griffith 1969), and these may not be representative of natural growth rates. Despite the uncertainties in estimating early juvenile growth and mortality, high early juvenile mortality is typical of many nektonic taxa (Sogard 1997), including brown shrimp in Galveston Bay (Minello et al. 1989). The inflection in the catch-curve indicating high early mortality for shrimp $<28 \mathrm{~mm}$ TL (the discontinuity at ca. 20 d age in Fig. 4 b) coincides with the change in our use of growth rate estimates. However, the inflection remains even if a constant growth rate is used to convert the entire length frequency (Fig. 4a) to age frequency (Fig. 4b) for catch-curve analysis. Thus, while the exact estimate may be uncertain, our observation of high early mortality is not an artifact of our estimated growth rates for small juvenile shrimp.

Minello et al. (2008) estimated daily instantaneous white shrimp (11 to $70 \mathrm{~mm}$ TL) mortality of 0.032 using catch-curve analysis from a database of drop samples collected from Galveston Bay saline marshes over $20 \mathrm{yr}$. They assumed a growth rate of $1.0 \mathrm{~mm} \mathrm{~d}^{-1}$. If we use our growth rates on their data, the overall estimate of $Z$ derived from the pooled database is 0.028 . Among years with sufficient temporal resolution in the database (16 yr), annual estimates ranged from 0.016 to 0.114 . Assuming the catch-curves are accurate representations of actual mortality rates, the trend was for mortality during most years to be close to the overall mean while occasionally being much higher. Similarly, Knudsen et al. (1996) reported daily $Z$ for juvenile white shrimp of between 0.02 and 0.07 in natural marsh ponds in Louisiana.

The estimates of $Z$ from the marsh pond in our study are close to the maximum estimates from other studies. These high estimates suggest that either juvenile shrimp mortality in the pond was relatively high during our study, or that our estimates were biased due to the potential violation of some of the assumptions of catch-curve analysis. Applying catch-curves to estimate mortality assumes that recruitment to the population is constant, mortality rate is constant, that the population is sampled randomly, and there is no postsettlement migration to or from the population (Ricker 1975). Recruitment during our study was variable with a particularly high abundance of PL sampled on August 2 (Fig. 3). This large pulse of recruitment would have the effect of inflating the abundance of young shrimp in the catch curve thereby elevating the estimate of $Z$. If the August 2 sample is excluded from the analysis, the mortality estimate for large juveniles would change to 0.081 compared to 0.083 . However, this pulse occurred early in the sampling period, so unless there was significant emigration of these individuals out of the pond population after recruitment, the subsequent decline in their abundance should represent mortality in the pond.

Water temperatures measured in the pond during the first growth experiment were higher and more variable than those in the adjacent bayou. Under certain conditions the shallow waters of the pond represent a more physically extreme habitat than adjacent 
areas of deeper water, and as a result, shrimp may emigrate from the pond soon after settlement, thus confounding the high mortality estimates in the present study. However, the mean density of shrimp in our marsh pond samples $\left(1.21 \pm 0.16 \mathrm{~m}^{-2}\right)$ was in close agreement with the $1.1 \mathrm{~m}^{-2}$ predicted by the density models of Minello et al. (2008) developed from hightide samples of saline Texas marshes over $20 \mathrm{yr}$. This close agreement indicates that the pond habitat is similar to other shallow open water areas in Texas.

The relationship we observed between shrimp abundance and water depth suggests that much of the migration of shrimp to the marsh surface occurs prior to water depths reaching $25 \mathrm{~cm}$ in the marsh edge (Fig. 5a). This relationship was weaker for larger shrimp (>15mm TL) (Fig. 5b), being partly driven by the abundance of early PL $<15 \mathrm{~mm}$, and is thus potentially confounded by recruitment events coincidentally occurring just prior to sampling dates when water levels in the pond were low. As a consequence, we could not confidently or accurately adjust our estimates of shrimp abundance based on the water depth-shrimp density relationship in an effort to refine our mortality estimates. It is apparent, however, that when the marsh surface is accessible to shrimp the abundance in adjacent open waters tends to be lower than when the marsh is not accessible (Fig. 5 this study) (Kneib 1995). This relationship should be expected given the high densities of white shrimp recorded on the vegetated marsh surface when it is flooded (Kneib \& Wagner 1994, Peterson \& Turner 1994, Howe et al. 1999, Minello et al. 2008).

There is some evidence of differential size distributions between vegetated and open water habitats in Galveston Bay for both white shrimp and brown shrimp, with proportionally more small shrimp in open waters and larger shrimp in marsh vegetation (Minello et al. 2008). Elsewhere authors have found the reverse to be true (Shervette \& Gelwick 2008). If larger shrimp in our pond population were more likely to access the marsh surface than small shrimp due to size-structured habitat selection or staggered recruitment of PL to vegetated habitats via open waters, our open-water sampling could under represent larger shrimp in the pond population, violating the assumption that we sampled the entire population randomly and resulting in the high estimates of $Z$.

Predation is a significant source of natural mortality for juvenile penaeid shrimp (Zimmerman et al. 2000), and brown shrimp suffer lower levels of predation mortality in vegetated marsh habitats than in adjacent open waters (Minello et al. 1989, Minello 1993). Assuming juvenile white shrimp gain similar refuge benefit on the marsh surface as brown shrimp, marsh flooding patterns may play an important role in regu- lating juvenile white shrimp mortality (Rozas 1995). Evidence from the growth experiments suggests that in the absence of predators, natural mortality of white shrimp in the pond is low. Between 83 and $86 \%$ of tagged shrimp were recovered from the cages at the end of our growth experiments, and missing experimental shrimp represent a combination of natural mortality in the absence of predators and recovery efficiency of shrimp from the cages. Field trials of the recovery method conducted prior to the growth experiments found that shrimp held in the cages for $<1 \mathrm{~h}$ were recovered at similar rates to those after the weeklong experiments, indicating recovery efficiency rather than mortality accounted for most missing shrimp.

\section{CONCLUSIONS}

Our growth estimates from an estuarine pond are broadly similar to the few other available estimates for white shrimp in the region, and they suggest that white shrimp growth varies little in different open water habitats. Measurements of growth in different estuarine habitats can provide an indicator of relative habitat value, but artifacts from experimental methods appear common. Because of the difficulty in caging nekton in intertidal habitats, there is a distinct lack of estimates of nekton growth on the vegetated marsh surface (Shervette \& Gelwick 2008, Rozas \& Minello 2009), yet such information is needed to address the long-held paradigm that occupation of marsh vegetation enhances growth (Zimmerman et al. 2000). Mortality estimates are difficult to obtain, and our rates were amongst the highest of the few available other estimates. This disparity may be an artifact of the sampling design and period or of violations of assumptions required for a reliable catchcurve analysis, or it may reflect real and natural variability in mortality rates in marsh habitats. We suggest that more attention should be placed on assessing whether assumptions have been met when developing mortality estimates. Despite the challenges, estimates of growth and mortality with comparisons among habitats form a fundamental component of the identification of essential habitats and understanding nursery-ground functioning for white shrimp and other nekton using coastal nurseries (Heck et al. 2003, Minello et al. 2003).

Acknowledgements. We thank the team in the Benthic Lab at NOAA Galveston for their assistance in the field, particularly S. Hillen, E. Wilson, J. Doerr, J. Salas, and M. Haverland. P. Caldwell performed the GIS analysis on the marsh pond. This research was performed while R.B. held a National Research Council Research Associateship Award at the NOAA Galveston Lab. L. Rozas provided helpful comments on a draft of this manuscript. We thank 4 anonymous reviewers for comments that also greatly improved the manuscript. 


\section{LITERATURE CITED}

Beck MW, Heck KL, Able K, Childers DL and others (2001) The identification, conservation, and management of estuarine and marine nurseries for fish and invertebrates. Bioscience 51:633-641

$>$ Beseres JJ, Feller RJ (2007) Importance of predation by white shrimp Litopenaeus setiferus on estuarine subtidal macrobenthos. J Exp Mar Biol Ecol 344:193-205

Beseres Pollack J, Mroch RM, Feller RJ (2008) Juvenile white shrimp Litopenaeus setiferus predation on macrobenthic and zooplanktonic prey. J Shellfish Res 27:1247-1253

Boesch DF, Turner RE (1984) Dependence of fishery species on salt marshes: the role of food and refuge. Estuaries 7: $460-468$

> Fry B (2008) Open bays as nurseries for Louisiana brown shrimp. Estuaries Coasts 31:776-789

Fry B, Baltz DM, Benfield MC, Fleeger JW, Gace A, Haas AL, Quinones-Rivera ZJ (2003) Stable isotope indicators of movement and residency of brown shrimp (Farfantepenaeus aztecus) in Louisiana marshscapes. Estuaries 26:82-97

Gayanilo FC, Sparre P, Pauly D (2005) FiSAT II. FAO, Rome

Heck KL Jr., Hays G, Orth RJ (2003) Critical evaluation of the nursery role hypothesis for seagrass meadows. Mar Ecol Prog Ser 253:123-136

Howe JC, Wallace RK, Rikard FS (1999) Habitat utilization by postlarval and juvenile penaeid shrimps in Mobile Bay, Alabama. Estuaries 22:971-979

> Hunter J, Feller RJ (1987) Immunological dietary analysis of two penaeid shrimp species from a South Carolina tidal creek. J Exp Mar Biol Ecol 107:61-70

Kneib RT (1995) Behaviour separates potential and realized effects of decapod crustaceans in salt marsh communities. J Exp Mar Biol Ecol 193:239-256

Kneib RT (1997) The role of tidal marshes in the ecology of estuarine nekton. Oceanog Mar Biol Annu Rev 35: 163-220

Kneib RT (2003) Bioenergetic and landscape considerations for scaling expectations of nekton production from intertidal marshes. Mar Ecol Prog Ser 264:279-296

Kneib RT, Wagner SL (1994) Nekton use of vegetated marsh habitats at different stages of tidal inundation. Mar Ecol Prog Ser 106:227-238

Knudsen EE, Rogers BD, Paille RF, Herke WH, Geaghan JP (1996) Juvenile white shrimp growth, mortality, and emigration in weired and unweired Louisiana marsh ponds. N Am J Fish Manag 16:640-652

McTigue TA, Zimmerman RJ (1991) Carnivory versus herbivory in juvenile Penaeus setiferus (Linnaeus) and Penaeus aztecus (Ives). J Exp Mar Biol Ecol 151:1-16

McTigue TA, Zimmerman RJ (1998) The use of infauna by juvenile Penaeus aztecus (Ives) and Penaeus setiferus (Linnaeaus). Estuaries 21:160-175

Minello TJ (1993) Chronographic tethering: a technique for measuring prey survival time and testing predation pressure in aquatic environments. Mar Ecol Prog Ser 101: 99-104

> Minello TJ, Rozas LP (2002) Nekton populations in Gulf Coast wetlands: fine-scale spatial distributions, landscape patterns, and restoration implications. Ecol Appl 12:441-455

Minello TJ, Zimmerman RJ (1985) Differential selection for vegetative structure between juvenile brown shrimp (Penaeus aztecus) and white shrimp (P. setiferus), and implications in predator-prey relationships. Estuar Coast Shelf Sci 20:707-716

Minello TJ, Zimmerman RJ, Martinez EX (1989) Mortality of young brown shrimp Penaeus aztecus in estuarine nurseries. Trans Am Fish Soc 118:693-708
Minello TJ, Able KW, Weinstein MP, Hays C (2003) Salt marshes as nurseries for nekton: testing hypotheses on density, growth, and survival through meta-analysis. Mar Ecol Prog Ser 246:39-59

- Minello TJ, Matthews GA, Caldwell PA (2008) Population and production estimates for decapod crustaceans in wetlands of Galveston Bay, Texas. Trans Am Fish Soc 137:129-146

Peterson CH, Black R (1994) An experimentalist's challenge: when artifacts of intervention interact with treatments. Mar Ecol Prog Ser 111:289-297

> Peterson GW, Turner RE (1994) The value of saltmarsh edge vs interior as habitat for fish and decapod crustaceans in a Louisiana tidal marsh. Estuaries 17:235-262

Pullen EJ, Trent WL (1969) White shrimp emigration in relation to size, sex, temperature, and salinity. Food Agricult Org Fish Report 3:1001-1014

Ricker W (1975) Computation and interpretation of biological statistics of fish populations. Vol 191. Canadian Department of the Environment Fisheries and Marine Service Bulletin, Ottawa

> Rosas C, Ocampo L, Gaxiola G, Sanches A, Soto LA (1999) Effect of salinity on survival, growth and oxygen consumption of postlarvae (PL10-PL21) of Litopenaeus setiferus. J Crustac Biol 19:244-251

Rountree RA, Able KW (2007) Spatial and temporal habitat use patterns for salt marsh nekton: implications for ecological functions. Aquat Ecol 41:25-45

Rozas LP (1995) Hydroperiod and its influence on nekton use of the saltmarsh: a pulsing ecosystem. Estuaries 18: $579-590$

Rozas LP, Minello TJ (1997) Estimating densities of small fishes and decapod crustaceans in shallow estuarine habitats: a review of sampling design with focus on gear selection. Estuaries 20:199-213

Rozas LP, Minello TJ (2009) Using nekton growth as a metric for assessing habitat restoration by marsh terracing. Mar Ecol Prog Ser 394:179-193

Rozas LP, Minello TJ, Zimmerman RJ, Caldwell P (2007) Nekton populations, long-term wetland loss, and the effect of recent habitat restoration in Galveston Bay, Texas, USA. Mar Ecol Prog Ser 344:119-130

Sheaves M, Baker R, Johnston R (2006) Marine nurseries and effective juvenile habitats: an alternative view. Mar Ecol Prog Ser 318:303-306

- Shervette VR, Gelwick F (2008) Relative nursery function of oyster, vegetated marsh edge, and nonvegetated bottom habitats for juvenile white shrimp Litopenaeus setiferus. Wetlands Ecol Manag 16:405-419

Sogard SM (1997) Size-selective mortality in the juvenile stage of teleost fishes: a review. Bull Mar Sci 60: 1129-1157

Webb S, Kneib RT (2004) Individual growth rates and movement of juvenile white shrimp (Litopenaeus setiferus) in a tidal marsh nursery. Fish Bull 102:376-388

Whaley SD, Minello TJ (2002) The distribution of benthic infauna of a Texas salt marsh in relation to the marsh edge. Wetlands 22:753-766

Zein-Eldin ZP, Griffith GW (1969) An appraisal of the effects of salinity and temperature on growth and survival of postlarval penaeids. FAO Fish Rep 3:1015-1026

Zimmerman RJ, Minello TJ (1984) Densities of Penaeus aztecus, $P$. setiferus and other natant macrofauna in a Texas salt marsh. Estuaries 7:421-433

Zimmerman RJ, Minello TJ, Rozas LP (2000) Salt marsh linkages to productivity of penaeid shrimps and blue crabs in the northern Gulf of Mexico. In: Weinstein MP, Kreeger DA (eds) Concepts and controversies in tidal marsh ecology. Kluwer, Dordrecht 